\title{
Ras Oncogene-Mediated Progressive Silencing of Extracellular Superoxide Dismutase in Tumorigenesis
}

\author{
Francesca Cammarota, ${ }^{1}$ Gabriella de Vita, ${ }^{2}$ Marco Salvatore, ${ }^{1}$ and Mikko O. Laukkanen \\ ${ }^{1}$ IRCCS SDN, 80143 Naples, Italy \\ ${ }^{2}$ Department of Molecular Medicine and Medical Biotechnologies, University of Naples Federico II, 80014 Naples, Italy \\ Correspondence should be addressed to Mikko O. Laukkanen; mlaukkanen@sdn-napoli.it
}

Received 15 June 2015; Accepted 31 August 2015

Academic Editor: Max Costa

Copyright (C) 2015 Francesca Cammarota et al. This is an open access article distributed under the Creative Commons Attribution License, which permits unrestricted use, distribution, and reproduction in any medium, provided the original work is properly cited.

Extracellular superoxide dismutase (SOD3) is a secreted enzyme that uses superoxide anion as a substrate in a dismutase reaction that results in the formation of hydrogen peroxide. Both of these reactive oxygen species affect growth signaling in cells. Although SOD3 has growth-supporting characteristics, the expression of SOD3 is downregulated in epithelial cancer cells. In the current work, we studied the mechanisms regulating SOD3 expression in vitro using thyroid cell models representing different stages of thyroid cancer. We demonstrate that a low level of RAS activation increases SOD3 mRNA synthesis that then gradually decreases with increasing levels of RAS activation and the decreasing degree of differentiation of the cancer cells. Our data indicate that SOD3 regulation can be divided into two classes. The first class involves RAS-driven reversible regulation of SOD3 expression that can be mediated by the following mechanisms: RAS GTPase regulatory genes that are responsible for SOD3 self-regulation; RASstimulated p38 MAPK activation; and RAS-activated increased expression of the mir21 microRNA, which inversely correlates with sod3 mRNA expression. The second class involves permanent silencing of SOD3 mediated by epigenetic DNA methylation in cells that represent more advanced cancers. Therefore, the work suggests that SOD3 belongs to the group of ras oncogene-silenced genes.

\section{Introduction}

The regulation of extracellular superoxide dismutase (SOD3) gene expression has remained challenging. Temporal stimulation of SOD3 expression could benefit tissue healing after injury [1-6], while long-term inhibition of overproduction of the enzyme could prevent unwanted hyperplasia [7]. According to recent publications, SOD3 supports a number of growth-stimulating events in tumorigenesis. Moderate sustained overexpression of SOD3 induces nontransformed murine primary cell proliferation, causing immortalization and neoplastic transformation [7]. In aggressive anaplastic cancer cells, moderate sustained overexpression of SOD3 stimulates tumorigenesis and growth factor signal transduction $[7,8]$. Moreover, SOD3 can control small GTPase activation and downstream signal transduction by modifying the expression of small GTPase regulatory genes $[8,9]$.

In tumorigenesis, genes that are expressed in normal cells but are disadvantageous for cancer development by inducing apoptosis [10], limiting cell proliferation [11], or correcting DNA damage [12] are downregulated through genetic events, such as deletions [13] and point mutations [14], epigenetic mechanisms, such as methylation and histone acetylation [15-17], and microRNA targeting affecting the gene transcription [18]. Intriguingly, SOD3, which has several growth-supporting characteristics, such as the ability to promote mitogenic and cell survival signaling, is frequently downregulated in advanced epithelial cancer cells. Thus, the role of SOD3 in tumorigenesis requires further study. To systematically characterize the concomitant mechanisms causing SOD3 downregulation in epithelial cancer cells, we utilized rat and human thyroid cell models harboring different oncogenes and representing variable degrees of differentiation. Based on our observations, sod 3 mRNA expression is progressively altered corresponding to RAS GTPase activation and carcinogenesis, thus further strengthening our previous observations suggesting a close cooperative connection between SOD3 and RAS. 


\section{Methods}

2.1. Cells. Rat thyroid PC Cl3, PC PTC1, PC E1A, and FRLT5 and the related cell clones V13, V21, and V27 stably transfected with an H-RasV12 expression plasmid [19] were cultured in Ham's F12 medium Coon's modified (Sigma, St. Louis, MO, USA) supplemented with $5 \%$ calf serum (Life Technologies, Inc., Carlsbad, CA), penicillin (100 U/mL) (Sigma), and streptomycin (100 mg/L) (Sigma). PC Cl3 and FRLT5 cells (modeling normal thyroid cells) were additionally supplemented with $10 \mathrm{nM}$ TSH, $10 \mathrm{nM}$ hydrocortisone, $100 \mathrm{nM}$ insulin, $5 \mathrm{mg} / \mathrm{mL}$ transferrin, $5 \mathrm{nM}$ somatostatin, and $20 \mathrm{mg} / \mathrm{mL}$ glycyl-histidyl-lysine. Human thyroid NTHY-ori 3.1 (Nthy) and anaplastic thyroid cancer 8505c cells were grown in RPMI medium (Life Technologies, Inc.) supplemented with $10 \%$ fetal bovine serum (Sigma), penicillin $(100 \mathrm{U} / \mathrm{mL})$, and streptomycin $(100 \mathrm{mg} / \mathrm{L})$. Human papillary thyroid cancer TPC1 cells were grown in DMEM supplemented with $10 \%$ fetal bovine serum, penicillin $(100 \mathrm{U} / \mathrm{mL})$, and streptomycin $(100 \mathrm{mg} / \mathrm{L})$. HEK $293 \mathrm{~T}$ cells were grown in DMEM supplemented with $10 \%$ fetal bovine serum, penicillin $(100 \mathrm{U} / \mathrm{mL})$, and streptomycin $(100 \mathrm{mg} / \mathrm{L})$. To study the regulation of $\operatorname{sod} 3$ gene expression, the cells were supplemented with $10 \mu \mathrm{M}$ 5-azacytidine (Sigma), $100 \mathrm{nM}$ TSA (Sigma), and $10 \mu \mathrm{M}$ SB202190 p38 MAPK inhibitor (Sigma) for 24 hours or with $\mathrm{H}_{2} \mathrm{O}_{2}$ (Sigma) for 6 hours.

The human SOD3 expression vector (a gift from Professor Stefan L. Marklund, University of Umea, Sweden), rabbit sod3 expression vector previously cloned in our group [20], or pcDNA3 control (Invitrogen, Paisley, UK) or H-RasV12 plasmid was transfected with Fugene 6 (Promega, WI, USA) according to standard protocols.

2.2. Real-Time Reverse Transcription PCR. Cells were pelleted for RNA isolation using an RNeasy Mini Kit (Qiagen, Hilden, Germany) and cDNA synthesis using a QuantiTect Reverse Transcription Kit (Qiagen). The PCR reaction was performed using an iCycler (BioRad, Hercules, CA, USA) and SYBR Green PCR Master Mix (Applied Biosystems, Foster City, CA). The primers were designed with (http://www.ncbi.nlm .nih.gov/tools/primer-blast/). Human $\beta$-actin and rat $\beta$-actin were used to normalize human and rat templates, respectively. Relative fluorescence expression values were calculated as follows: $\Delta \mathrm{Ct}=\mathrm{Ct}$ (gene of interest)-Ct ( $\beta$-actin) $\Delta \Delta \mathrm{Ct}=$ $\Delta \mathrm{Ct}$ (treated) $-\Delta \mathrm{Ct}$ (control). Relative expression values = $2^{(-\Delta \Delta \mathrm{Ct})}$. The primers are listed in Table 1 .

2.3. MicroRNA Isolation. MicroRNA was isolated using an miRNeasy Kit (Qiagen) for reverse transcription with a miScript RT II Kit (Qiagen). The miR21 and RNU5 miScript Primer Assays (Qiagen) were used for amplification and to normalize the miR21 expression.

2.4. Western Blot. The cells were harvested in lysis buffer (50 mM HEPES, pH 7.5, 150 mM NaCl, 10\% glycerol, 1\% Triton X-100, $1 \mathrm{mM}$ EGTA, $1.5 \mathrm{mM} \mathrm{MgCl}$, $10 \mathrm{mM} \mathrm{NaF,} 10 \mathrm{mM}$ sodium pyrophosphate, $1 \mathrm{mM} \mathrm{Na} \mathrm{VO}_{4}, 10 \mu \mathrm{g}$ aprotinin/mL, and $10 \mu \mathrm{g}$ leupeptin/mL), separated by sodium dodecyl
TABLE 1: PCR primer sequences used in the study.

\begin{tabular}{lc}
\hline Human SOD3 forward & cttcgctctgctgaagtct \\
Human SOD3 reverse & gggtgtttcggtacaaatgg \\
Rat sod3 forward & gacctggagatctggatgga \\
Rat sod3 reverse & gtggttggaggtgttctgct \\
${ }^{*}$ Rabbit sod3 forward & gttgcgtgagcggaaaga \\
Rabbit sod3 reverse & gtgagcgcctgccagatctc \\
Human SOS1 forward & cacctcctcctcaaacacct \\
Human SOS1 reverse & gtgtgtgtgctccttttgt \\
Human SOS2 forward & ttttgaagaacgggtggcag \\
Human SOS2 reverse & ttttcctttcctgcagtgcc \\
Human $\beta$-actin forward & tgcgtgacattaaggagaag \\
Human $\beta$-actin reverse & gctcgtagctcttctcca \\
Rat $\beta$-actin forward & tcgtgcgtgacattaaggag \\
Rat $\beta$-actin reverse & gtcaggcagctcgtagctct \\
\hline
\end{tabular}

* Primer designed against EFlalfa promoter.

sulfate-polyacrylamide gel electrophoresis, and transferred to Hybond C Extra nitrocellulose membranes (GE Healthcare, WI, USA). The following antibodies were used: $p E r k 1 / 2$, Erk1/2, p-p38 MAPK, and p38 MAPK (Cell Signaling Technology, MA, USA).

2.5. Statistical Analysis. The experiments were repeated at least three times. All of the results were expressed as the mean values \pm SD. The $p$ values $\left({ }^{*} p<0.05,{ }^{* *} p<0.01\right.$, and ${ }^{* * *} p<$ $0.001)$ were determined using two-tailed independent sample $t$-tests.

\section{Results}

3.1. Thyroid Cell Models Representing Different Degrees of Thyroid Cancer. Thyroid stimulating hormone, hydrocortisone, insulin, transferrin, somatostatin, and glycyl-histidyl-lysine supplementation-dependent FRLT5 cells are a clonal cell line derived from rat normal thyroid FRLT cells by purification through successive isolation of colonies [21]. FRLT5 clones $\mathrm{V} 13, \mathrm{~K} 20, \mathrm{~K} 2, \mathrm{~V} 21, \mathrm{~V} 39$, and V27 were created by stable transfection with $H$-RasV12 oncogene followed by clonal expansion of the cell lines derived from a single cell. The clone V13 harbors 1.4-fold, K20 3.1-fold, K2 6.3-fold, V21 10-fold, V39 35-fold, and V27 46-fold RAS activity relative to parental cells. This increased RAS activity drives the growth of the cells without hormone supplementation, thus modeling the hormone-independent growth characteristics of thyroid cancers [19]. Similar to FRLT5 cells, PC Cl3 cells represent rat normal thyroid cells and are dependent on hormone supplementation [22]. PC PTC1 and PC E1A clones are PC $\mathrm{Cl} 3$ derivatives that were transformed with PTC1 and E1A oncogenes [23]. PTC1 is a papillary thyroid cancer- (PTC-) associated oncogene derived from a genomic rearrangement of the RET oncogene with the CDC61/H4 gene [24]. The E1A oncogene shows structural and functional similarities to the $M Y C$ and $M Y B$ oncogenes [25] that mechanistically bypass 


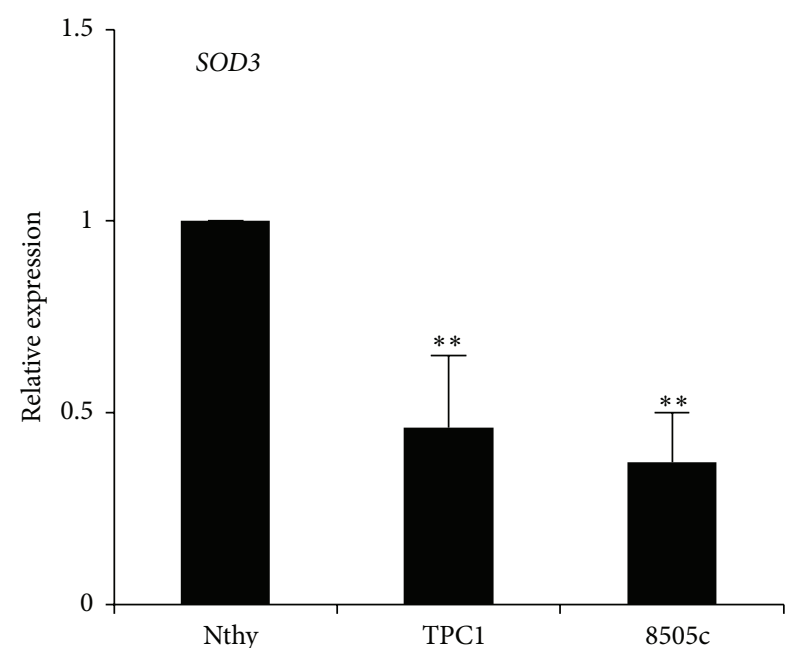

(a)

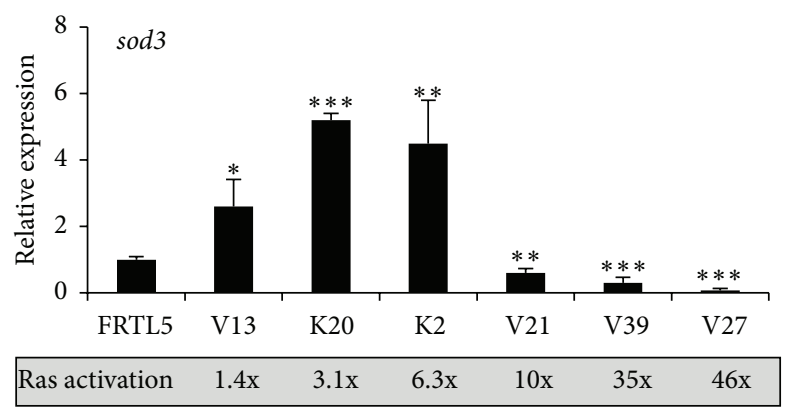

(c)

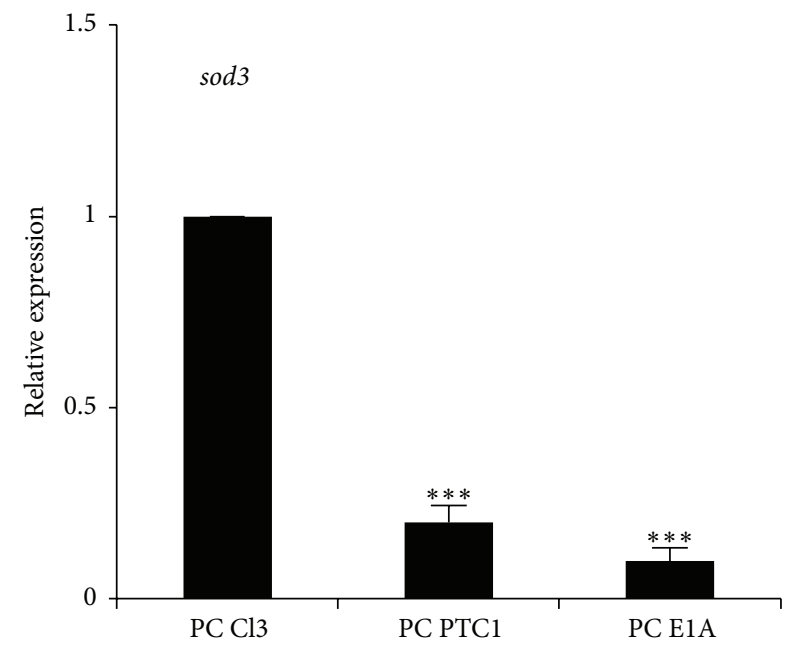

(b)

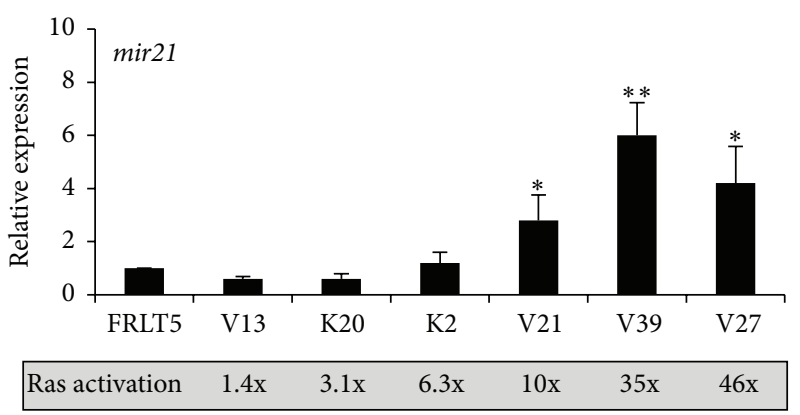

(d)

FIGURE 1: SOD3 mRNA expression level in the cell model systems used in this study. (a) SOD3 expression analysis in human papillary thyroid TPC1 and anaplastic thyroid 8505c cells showed significantly reduced mRNA expression compared to Nthy cells representing normal thyroid. (b) The sod 3 mRNA expression from rat thyroid PC Cl3 cells modeling normal thyroid, PC PTC1 transformed with the PTC1 oncogene, and PC E1A cells transformed with the E1A oncogene. The oncogenic transformation of PC Cl3 cells caused a downregulation of sod3 mRNA. (c) The expression analysis of sod3 from rat FRLT5 cell clones harboring 1.4-fold to 46-fold increased RAS activity compared to control FRLT5 cells suggested significantly increased sod3 expression in the clones V13 (1.4-fold RAS activity), K20 (3.1-fold RAS activity), and K2 (6.3-fold RAS activity). A significant decrease in sod3 mRNA synthesis was observed in the clone V21 (10-fold RAS activity) that was further reduced in the clones V39 (35-fold RAS activity) and V27 (46-fold RAS activity). (d) The expression analysis of the microRNA mir21 from FRLT5 cells. Compared to control FRLT5 cells, the expression levels of mir21 were similar in the clones V13 (1.4-fold RAS activity), K20 (3.1-fold RAS activity), and K2 (6.3-fold RAS activity). A significant increase in expression was observed in the clones V21 (10-fold RAS activity), V39 (35-fold RAS activity), and V27 (46-fold RAS activity). The data are expressed as the mean \pm SD. The $p$ values are represented $\left({ }^{*} p<0.05\right.$, ${ }^{* *} p<0.01$, and $\left.{ }^{* * *} p<0.001\right)$.

the proliferative block of terminally differentiated cells by increasing the activity of cell cycle-related proteins [26].

To model normal human thyroid, we utilized SV40immortalized Nthy cells [27], which are able to grow without hormone supplementation. TPC1 cells, which are spontaneously transformed thyroid cancer cells isolated from a patient, represent well-differentiated papillary thyroid cancer in this study. The $8505 \mathrm{c}$ cell line originates from a patient with undifferentiated highly aggressive anaplastic thyroid cancer harboring mutant p53 [28] and a BRAF V600E mutation, resulting in constitutively active MEK-ERK kinase signaling with consequent uncontrolled cell proliferation and tumorigenesis [29]. HEK 293T cells derived from human embryonic kidney cells by adenovirus 5 transduction were used in the study to corroborate observations from thyroid cell model systems because of their strong growth and untroublesome transfection characteristics.

\subsection{RAS Activation Correlates with sod3 and mir21 Expression.} To validate the cell models for the aims of the current study, we investigated the expression of SOD3 mRNA. SOD3 expression was gradually downregulated in papillary thyroid cancer TPC1 cells and anaplastic thyroid cancer 8505 c cells compared to control Nthy cells modeling normal thyroid cells (Figure 1(a)), suggesting a correlation between the mRNA expression and the degree of differentiation of the cancer $[7,30]$. We observed a similar downregulation of sod 3 mRNA synthesis in $\mathrm{PC} \mathrm{Cl} 3$ cells transformed with other oncogenes (Figure 1(b)), confirming the oncogene-dependent regulation that has previously been observed [30]. According to a 
recent report, transfection of $H$-RasV12, b-raf, mek, and erk into cells stimulates SOD3 production [9]. To investigate the mechanism by which increased activation of RAS controls sod3 mRNA production, we utilized rat thyroid FRLT5 cell line clones stably transfected with varying amounts of the H-RasV12 oncogene [19]. Increased RAS activation of 1.4fold to 6.3-fold stimulated sod3 expression, whereas 10-fold RAS activation caused a striking decrease in the mRNA production that was further enhanced at 35-fold and 46-fold RAS activation levels (Figure 1(c)).

A recent report has suggested that mir21 targets the SOD3 $3^{\prime}$ UTR and results in RNAi-mediated silencing of the gene expression [31]. We assessed mir21 expression in the FRLT5 and FRLT5-derived clones and observed increased microRNA production that correlated with increased RAS activity [19]. Low 1.4- to 6.3-fold increased RAS activation did not increase mir21 production, whereas a significant strong induction was observed with 10-fold RAS activation (Figure 1(d)). These data corroborate the connection between sod3 and mir21 expression.

3.3. RAS-Induced p38 MAPK Phosphorylation Inhibits sod3 $m R N A$ Expression. A previous study has suggested that activation of p38 MAPK, one of the RAS downstream target cellular kinases, contributes to the regulation of SOD3 production [32]. We therefore investigated the effect of the p38 MAPK inhibitor SB202190 on SOD3 mRNA synthesis in the thyroid cell models.

Inhibition of the kinase had a minor impact on the SOD3 gene expression in human Nthy cells (Figure 2(a)), whereas SOD3 expression was significantly increased in human TPC1 papillary thyroid cancer cells and in human $8505 \mathrm{c}$ anaplastic thyroid cancer cells (Figures 2(b) and 2(c)). These data suggest that p38 MAPK downregulates SOD3 mRNA synthesis in advanced thyroid cancer cells. The expression data from PC $\mathrm{Cl} 3$ cells, PC PTC1 cells transformed with the papillary thyroid cancer PTC oncogene, and PC E1A cells immortalized with the aggressive adenovirus E1A oncogene (Figures 2(d)2(f)) treated with the p38 inhibitor indicated similar upregulation of sod3 expression, suggesting oncogene-dependent silencing of sod3 via p38 MAPK activation. The oncogenederived effect on p38 MAPK activation and sod3 downregulation was then studied in FRLT5 cells. In accord with the other cell models used, the kinase inhibitor minimally affected FRLT5 cells, whereas a significant increase in mRNA production was observed in FRLT5 clones V13, V21, and V39 harboring 1.4-fold, 10-fold, and 35-fold RAS activity (Figures $2(\mathrm{~g})-2(\mathrm{j}))$. Thus, the data corroborate previous observations [32] suggesting that activation of RAS through p38 MAPK downregulates sod3 expression, whereas inhibition of p38 MAPK phosphorylation increases sod $3 \mathrm{mRNA}$ production.

We then analyzed the p38 MAPK phosphorylation status in FRLT5 cells and related clones. The analysis showed significantly increased phosphorylation levels in the clones V13, V21, and V39 corresponding to RAS activation, hence corroborating p38 MAPK inhibitor results and suggesting that the RAS-p38 MAPK signal transduction pathway controls sod3 mRNA synthesis (Figures $2(\mathrm{k})$ and $2(\mathrm{~m})$ ).
The involvement of the RAS-p38 MAPK signaling pathway was further confirmed by transient transfection of HEK $293 \mathrm{~T}$ cells with increasing concentrations of the H-RasV12 oncogene; the increase in H-RasV12 levels correlated with increased p38 MAPK phosphorylation (Figures 2(l) and $2(n))$.

3.4. Cancer-Induced Hypermethylation Downregulates sod3 $m R N A$ Expression. The coding sequence of the sod3 gene is located in a hypermethylated CpG island [33], which suggests that methylation is involved in the regulation of the gene expression. Treatment with the hypomethylation agent 5azacytidine did not affect SOD3 mRNA expression in human Nthy cells, rat PC Cl3 cells, rat FRLT5 cells, or FRLT5 clone V13 containing a modest 1.4 -fold increased RAS activation level (Figures 3(a), 3(d), 3(g), and 3(h)); these results are consistent with our previous data showing no impact of hypomethylation on sod 3 expression in aortic smooth muscle cells representing normal vascular tissue [33]. However, the 5-azacytidine treatment significantly increased SOD3 expression in the human papillary thyroid cancer TPC1 and human anaplastic thyroid cancer 8505c cells (Figures 3(b) and 3(c)). Similarly, rat thyroid PC PTC1 and PC E1A cells (Figures 3(e) and 3(f)) and FRLT5 cell clones V21 and V39 with 10 -fold and 35-fold increased RAS activation, respectively, demonstrated increased sod 3 mRNA expression (Figures 3(i) and $3(\mathrm{j}))$. The results thus suggest that methylation-mediated SOD3 downregulation in cancer corresponds to the degree of differentiation of the cancer and to the activation level of the RAS small GTPase.

3.5. Histone Acetylation Affects sod3 mRNA Expression in Cells That Model Normal Thyroid Tissue. Histone deacetylases regulate the expression of genes involved in the initiation of tumorigenesis. Deacetylation creates a tight nonpermissive chromatin conformation that inhibits transcription. The histone deacetylation inhibitor trichostatin A (TSA) interferes with the histone deacetylase function of removing the acetyl groups from the histones, therefore increasing the histone acetylation level and resulting in the formation of an open euchromatin structure. Treatment with TSA significantly $(p<0.001)$ decreased sod3 mRNA expression in all of the thyroid cells that model normal thyroid (Figures 4(a), $4(\mathrm{~d})$, and $4(\mathrm{~g})$ ), while only a tendency towards increased expression was observed in transformed and cancer cells (Figure 4).

3.6. Self-Regulation of sod3 Expression Is Controlled by RAS Small GTPase Regulatory Genes. Our previous results have demonstrated SOD3-driven increased RAS GTP loading and RAS-ERK1/2-derived sod3 mRNA expression, therefore suggesting a self-regulatory loop for SOD3 [9]. This observation was further corroborated by data indicating that SOD3 causes increased growth signaling at moderate expression levels [7] and inhibits activation of the small GTPases RAS, RAC, CDC42, and RHO at high enzyme levels [8]. To evaluate the concentration-dependent self-regulation of SOD3, we transfected $0.25 \mu \mathrm{g}$ and $10 \mu \mathrm{g}$ of human SOD3 into the rat 


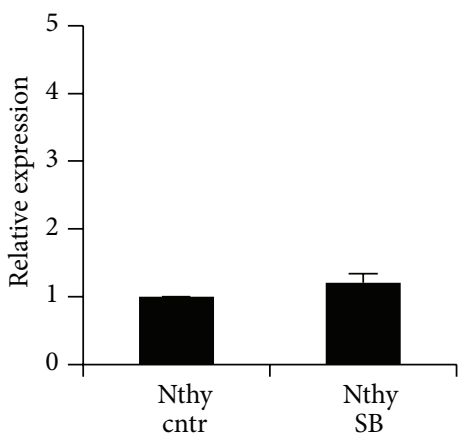

(a)

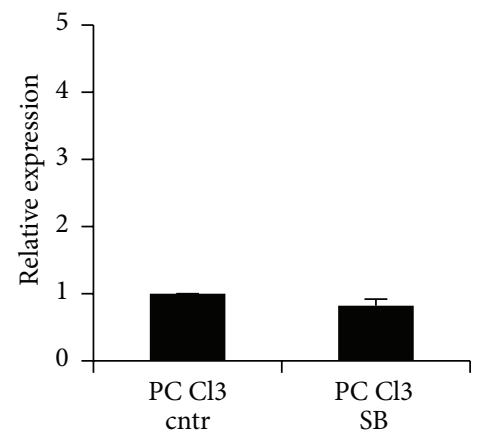

(d)

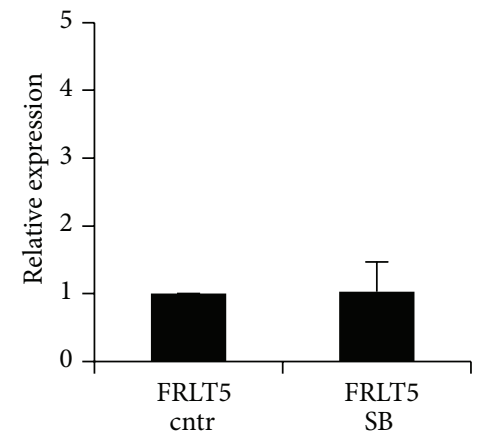

(g)

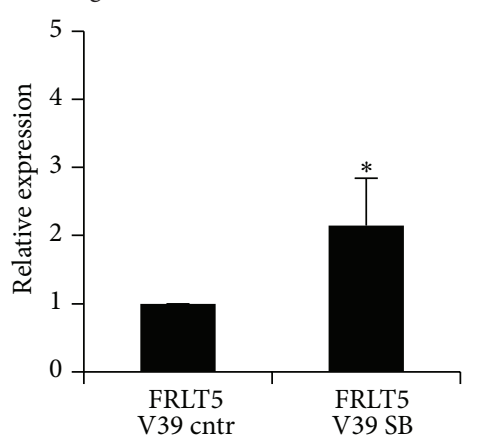

(j)

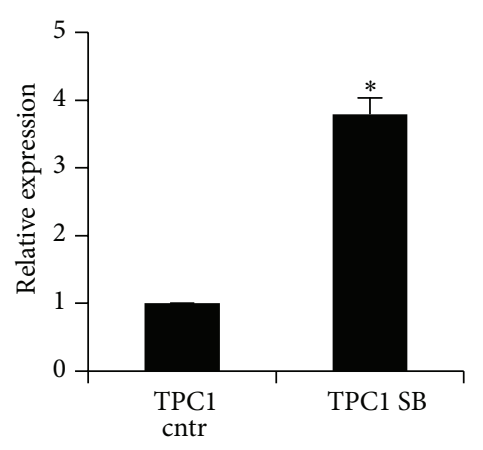

(b)

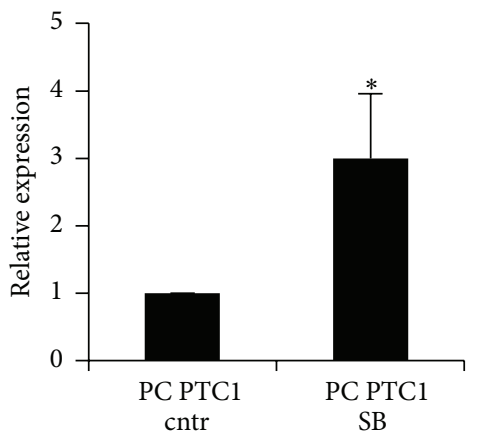

(e)

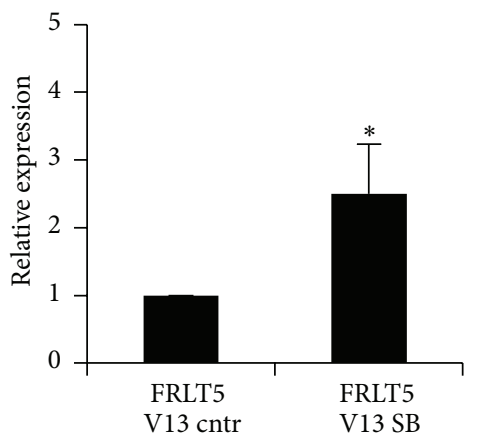

(h)

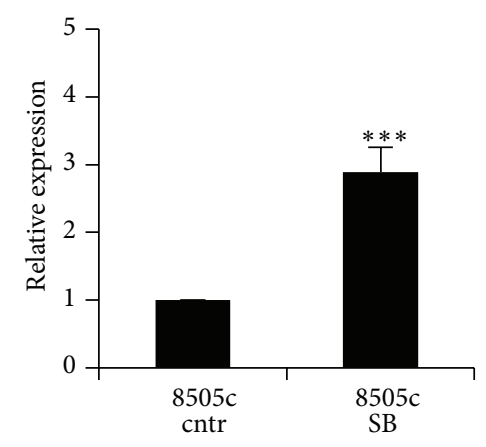

(c)

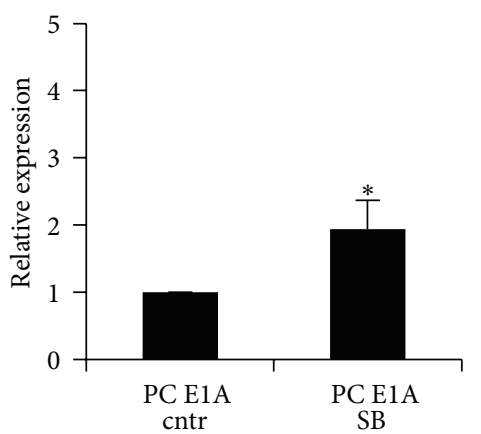

(f)

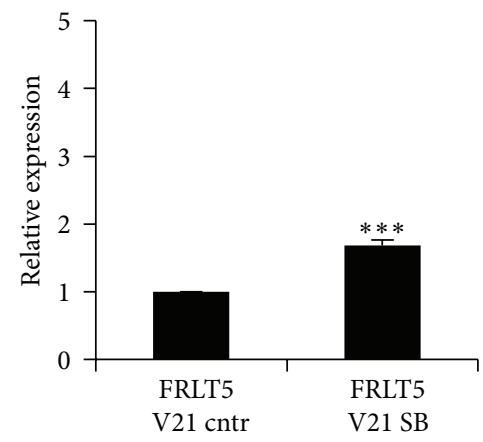

(i)

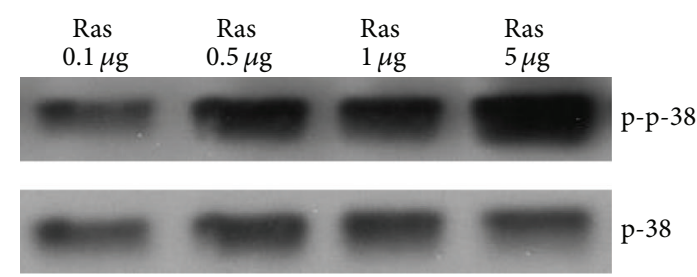

(l)

Figure 2: Continued. 

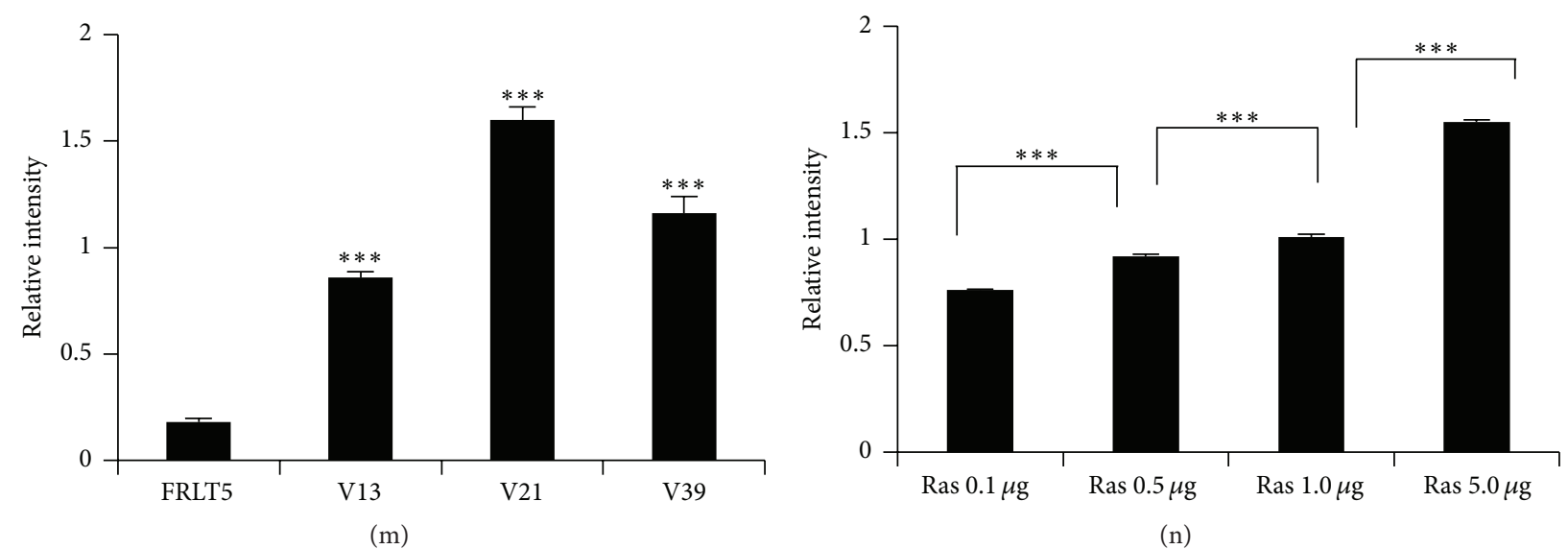

(n)

FIGURE 2: Effect of the p38 MAPK inhibitor SB202190 on SOD3 mRNA expression. (a-c) The inhibition of p38 MAPK phosphorylation increased the SOD3 expression in human TPC1 and 8505c cells, while SB202190 treatment did not alter the SOD3 mRNA synthesis in Nthy cells modeling normal thyroid. (d-f) The inhibitor treatment increased sod3 mRNA expression in PC Cl3-derived PC PTC1 and PC E1A cells, while the treatment had no effect on PC Cl3 control cells modeling normal thyroid. (g-j) FRLT5 cell clones V13, V21, and V39 stably transfected with RAS showed a significant increase in sod3 mRNA expression after SB202190 treatment, whereas SB202190 had no effect on FRLT5 control cells, which is consistent with the results using the other cell models. $(\mathrm{k}, \mathrm{m})$ The Western blot analysis for p38 MAPK activation in FRLT5 control cells, clone V13, clone V21, and clone V39. The histogram (panel (m)) suggested significantly increased p38 MAPK phosphorylation in FRLT5-derived clones compared to control cells. Total p38 MAPK was used to normalize the phosphorylation level. $(\mathrm{l}, \mathrm{n})$ The transient transfection of an H-RasV12 expression plasmid into HEK 293T cells showed a gradual increase in p38 MAPK phosphorylation that corresponded to the amount of plasmid transfected. Total p38 MAPK was used to normalize the phosphorylation level. The data are expressed as the mean $\pm \mathrm{SD}$. The $p$ values are represented $\left({ }^{*} p<0.05,{ }^{* *} p<0.01\right.$, and $\left.{ }^{* * *} p<0.001\right)$.

thyroid PC E1A cell line, which expresses low levels of endogenous sod3 mRNA. Transfection with low amounts of human SOD3 significantly increased the rat sod3 expression (Figure 5(a)), whereas transfection with high amounts of SOD3 had the opposite effect, significantly decreasing rat sod3 mRNA synthesis (Figure 5(b)). These data were supported by Western blot analysis suggesting a SOD3 dose-dependent activation of ERK1/2 kinase in PC E1A cells (Figures 5(c) and $5(\mathrm{~d})$ ). We have previously demonstrated that ERK1/2 stimulates endogenous SOD3 expression [9]. To corroborate the dose-dependent self-regulation, we transfected rabbit sod3 into human HEK $293 \mathrm{~T}$ cells and analyzed speciesspecific mRNA production on consecutive days. While the rabbit sod3 transgene expression decreased with increasing time from transfection, the endogenous human SOD3 mRNA production increased to maintain the total rabbit/human sod3 mRNA expression at similar levels on different days (Figure 5(e)). Because the only known physiological function of SOD3 is to dismutase superoxide to hydrogen peroxide, we investigated the effect of hydrogen peroxide on SOD3 mRNA synthesis. Treatment with low levels of $\mathrm{H}_{2} \mathrm{O}_{2}$ increased the endogenous SOD3 expression, while treatment with high levels of $\mathrm{H}_{2} \mathrm{O}_{2}(1 \mathrm{mM}$ and $10 \mathrm{mM})$ significantly decreased the mRNA production (Figure 5(f)); these data support the dosedependent self-regulation data.

We have recently demonstrated that SOD3 activates a number of tyrosine kinase receptors, cell membraneassociated nontyrosine kinases, and cellular kinases [8, 9, 34]. Based on our recent data, SOD3 regulates mitogen signal transduction by controlling the expression of small GTPase regulatory genes, including guanine nucleotide exchange factors (GEF), GTPase activating proteins (GAP), and guanosine nucleotide disassociation inhibitors (GDI), thus regulating the activation level of RAS [8]. In the present work, we investigated in $8505 \mathrm{c}$ cells the effects of low and high SOD3 expression levels on the guanine nucleotide exchange factor genes SOS1 and SOS2, which are responsible for RAS GTP loading. The data suggested that SOS1 and SOS2 mRNA expression is higher in cells that harbor low SOD3 mRNA content compared to cells with high SOD3 mRNA synthesis (Figures 5(g) and 5(h)). The data are in agreement with our previous results, in which we have shown increased growth and increased RhoGEF16 and RalGEF RGL1 expression with moderately increased SOD3 mRNA levels, whereas high SOD3 expression led to decreased growth and RhoGEF16 and RalGEF RGL1 expression [8]. Hence, the results suggest that SOD3 self-regulation is coordinated through guanine nucleotide exchange factors that are responsible for RAS activation.

\section{Discussion}

The signal transduction-related events that stimulate or inhibit SOD3 expression have previously been described and suggest the involvement of cytokines [35, 36], epigenetic regulation [37, 38], MAP kinases [9, 32], and the microRNA mir21 [31]. While the expression of the SOD3 enzyme is relatively stable in normal tissues, a significant increase in sod3 mRNA levels has been observed in rat thyroid benign tumors [30] with sequential downregulation of expression in carcinogenesis that corresponds to the degree of differentiation of the cells [30]. To characterize the cellular mechanisms 


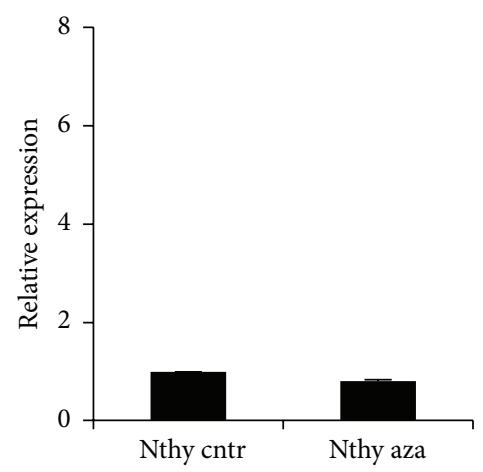

(a)

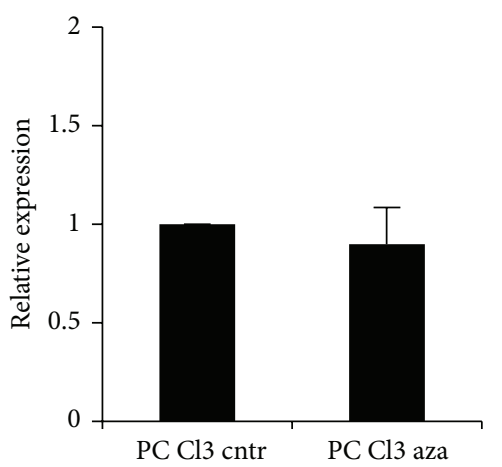

(d)

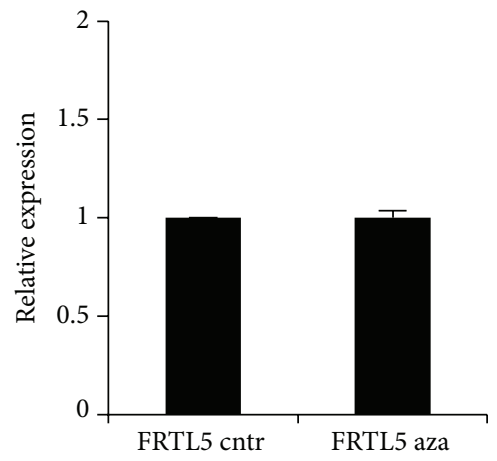

(g)

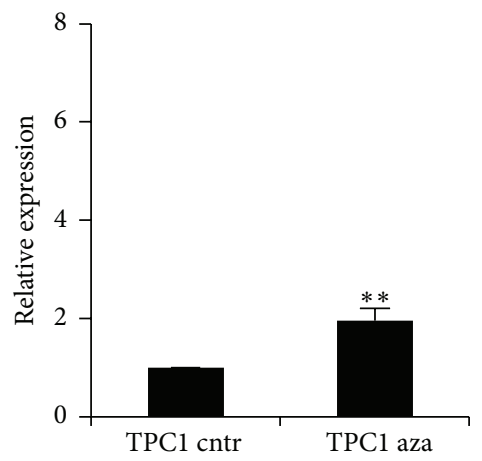

(b)

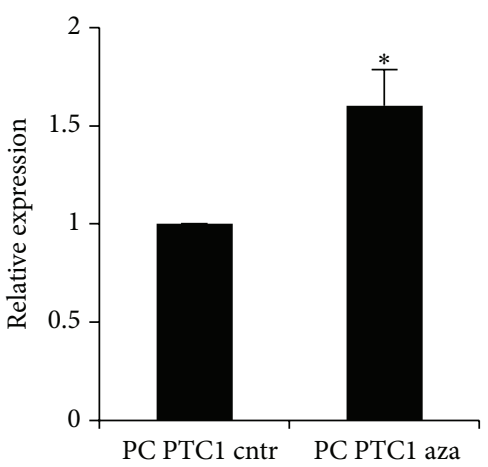

(e)

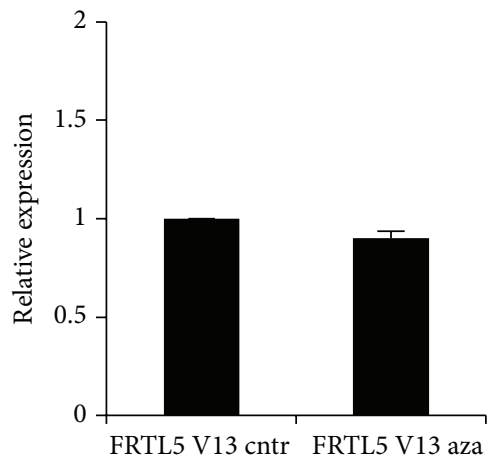

(h)

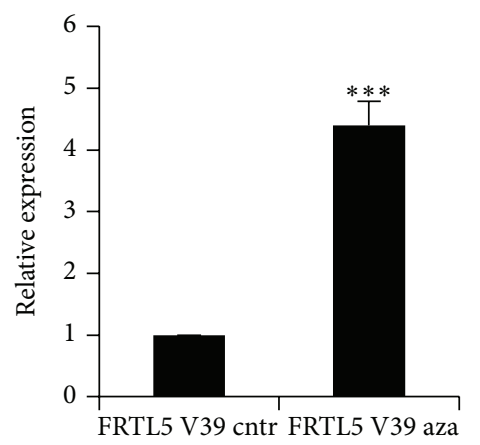

(j)

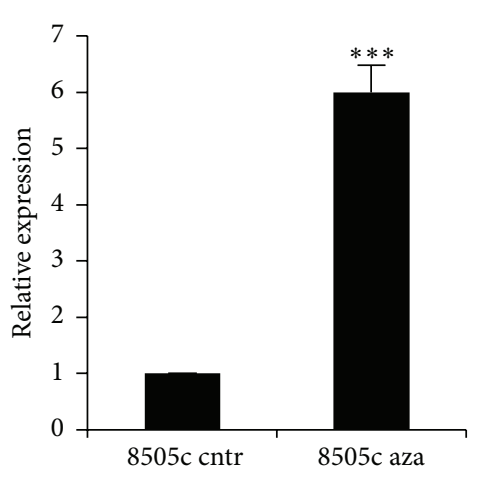

(c)

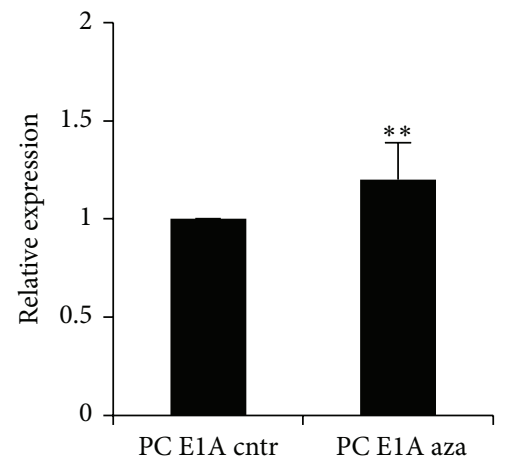

(f)

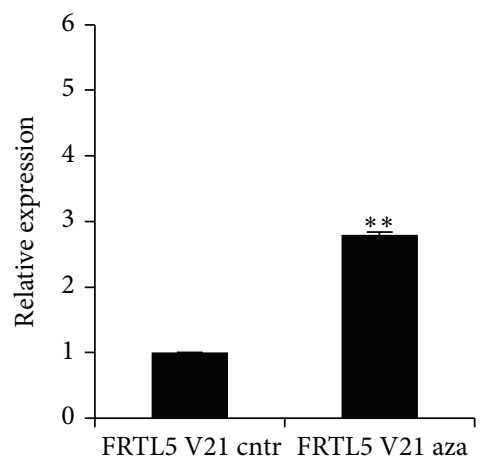

(i) FIGURE 3: Effect of the demethylation reagent 5-azacytidine on SOD3 mRNA expression. (a-c) Nthy cells modeling normal human thyroid
cells showed similar SOD3 mRNA expression in nontreated and treated control cells, whereas the mRNA production was significantly increased in 5-azacytidine-treated papillary TPC1 and anaplastic $8505 \mathrm{c}$ thyroid cancer cells. (d-f) Similar to the human cells, no alteration in sod3 mRNA was observed in rat PC Cl3 cells modeling normal rat thyroid cells after hypomethylation treatment, whereas the treatment induced increased mRNA synthesis in PTC1 and E1A oncogene-transfected cells. (g-j) The hypomethylation treatment did not affect normal rat thyroid FRLT5 cells or FRLT5 clone V13 cells harboring low 1.4-fold RAS activity, whereas a significant increase in the sod3 mRNA production was observed in clones V21 and V39 harboring 10-fold and 35-fold RAS activity, respectively. The data are expressed as the mean $\pm \mathrm{SD}$. The $p$ values are represented $\left({ }^{*} p<0.05,{ }^{* *} p<0.01\right.$, and $\left.{ }^{* * *} p<0.001\right)$. 


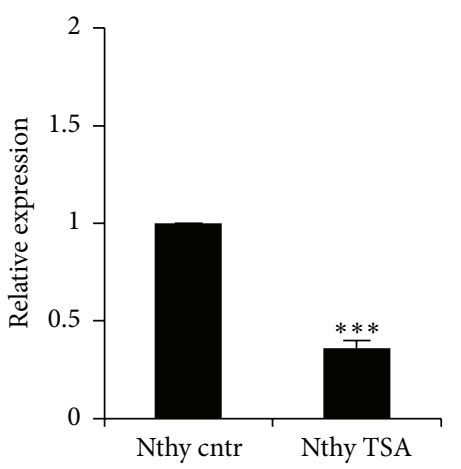

(a)

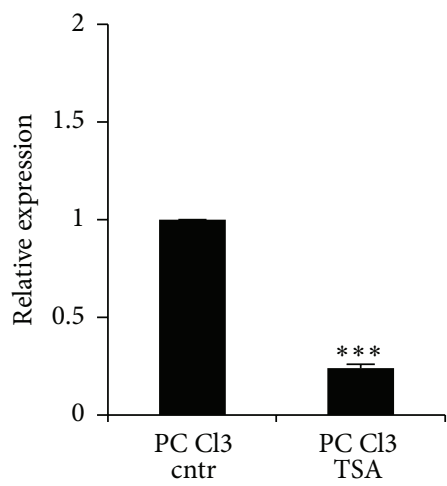

(d)

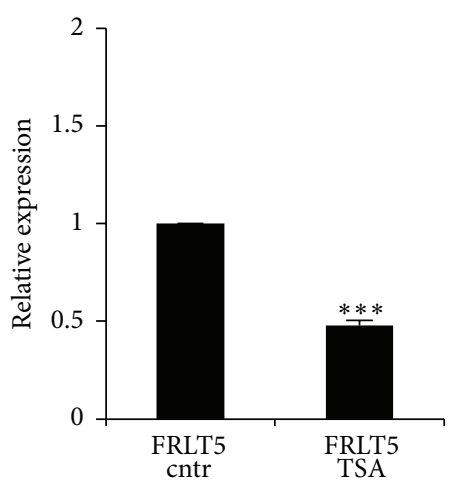

(g)

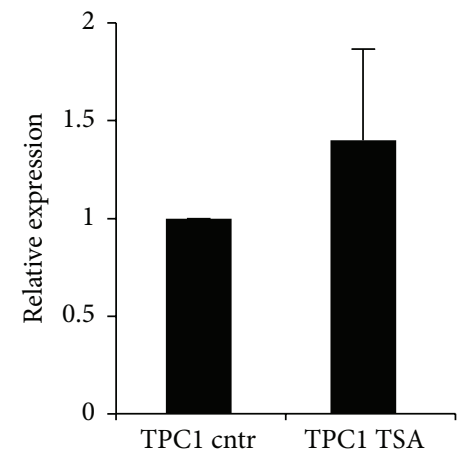

(b)

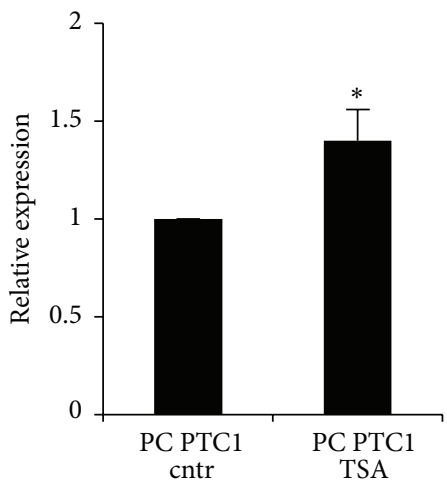

(e)

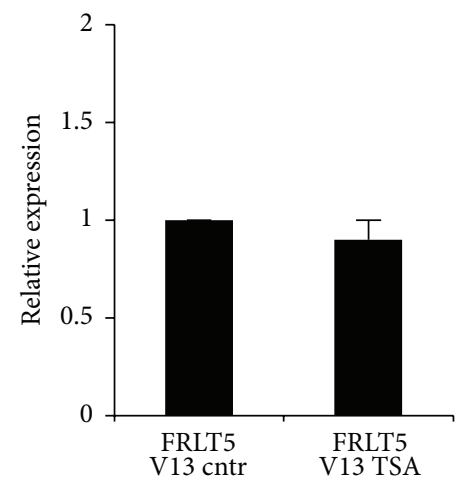

(h)

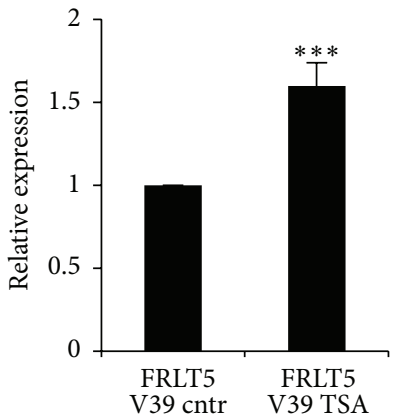

(j)

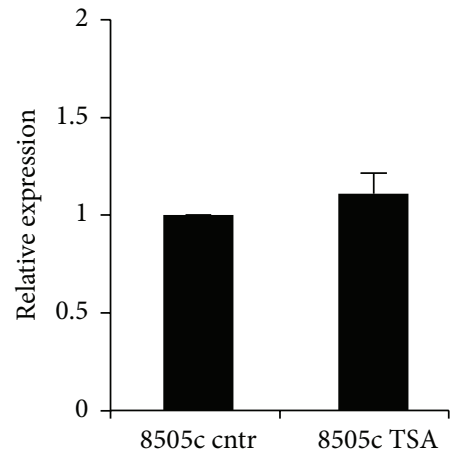

(c)

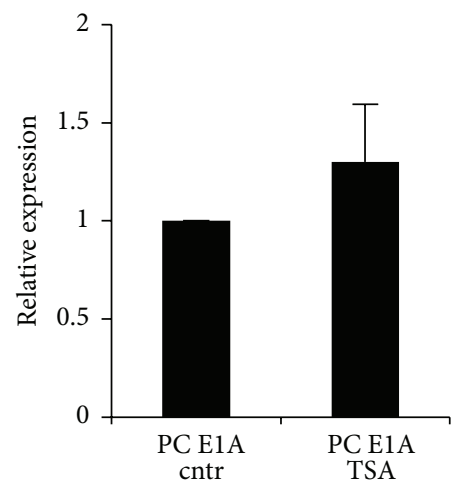

(f)

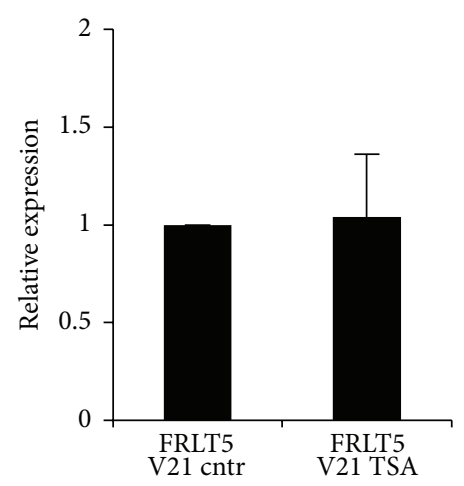

(i)

FIGURE 4: Effect of the histone deacetylation inhibitor trichostatin A (TSA) on SOD3 mRNA expression. (a-c) Human thyroid cells showed reduced SOD3 mRNA production in Nthy cells modeling normal thyroid cells and no alteration in papillary thyroid cancer TPC1 or anaplastic thyroid cancer $8505 \mathrm{c}$ cells. (d-f) The expression analysis from PC Cl3 cells supported the data obtained from the human cells; sod 3 expression was significantly reduced in control PC Cl3 cells and not altered in E1A transfected cells. (g-j) TSA treatment led to decreased sod3 expression in FRLT5 cells modeling normal thyroid but did not affect expression in clone V13 or V21 stably transfected with the H-RasV12 oncogene. TSA treatment increased sod3 mRNA synthesis only in PC PTC1 and FRLT5 V39 cells. The data are expressed as the mean \pm SD. The $p$ values are represented $\left({ }^{*} p<0.05,{ }^{* *} p<0.01\right.$, and $\left.{ }^{* * *} p<0.001\right)$. 


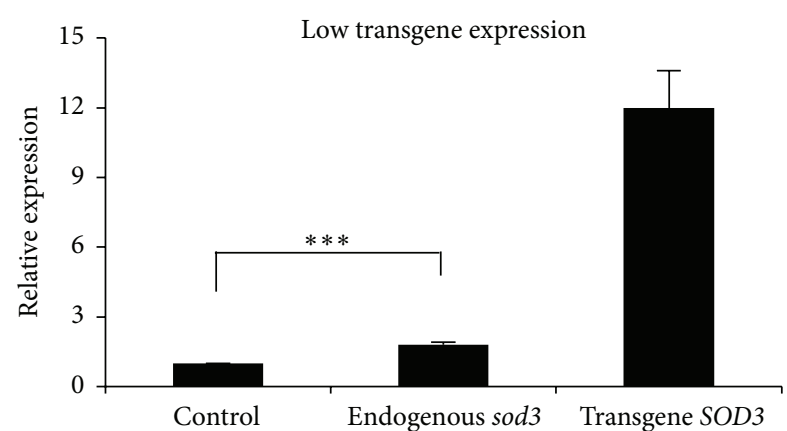

(a)

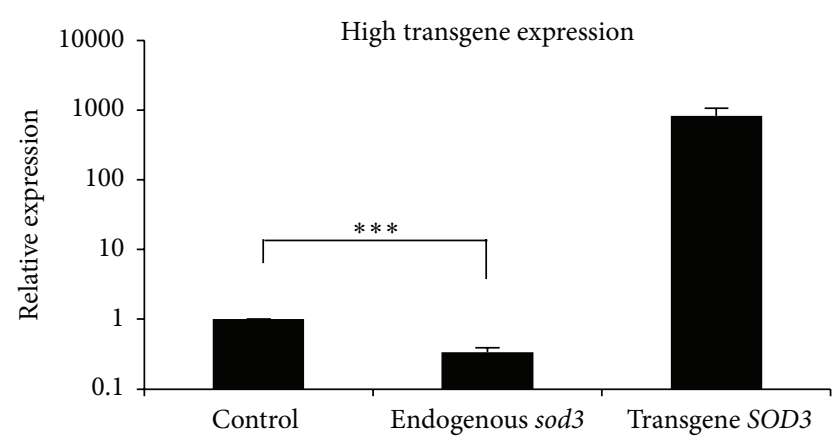

(b)
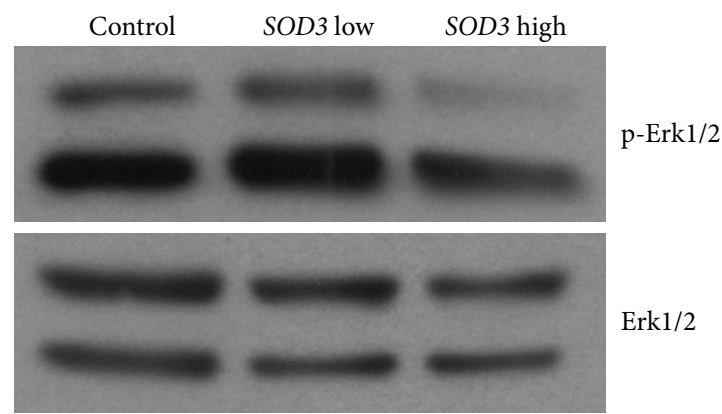

Erk1/2

(c)

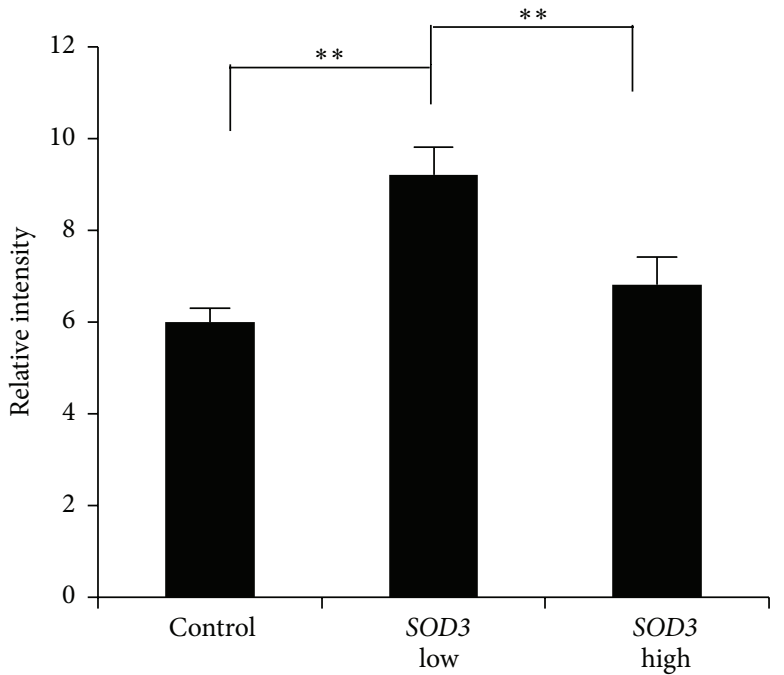

(d)

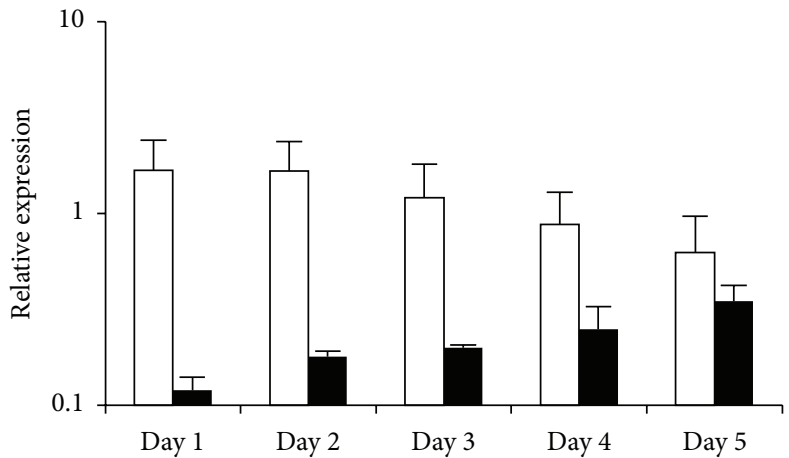

Transgene sod 3

Endogenous SOD3

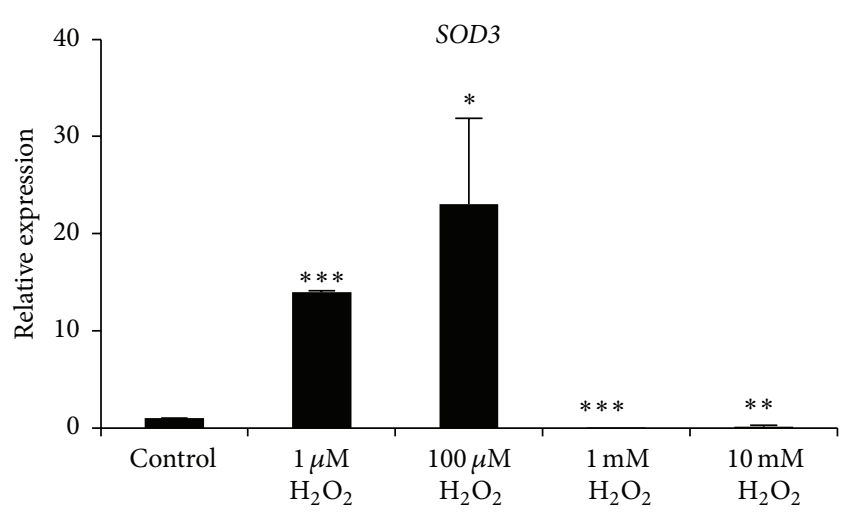

(e)

Figure 5: Continued. 


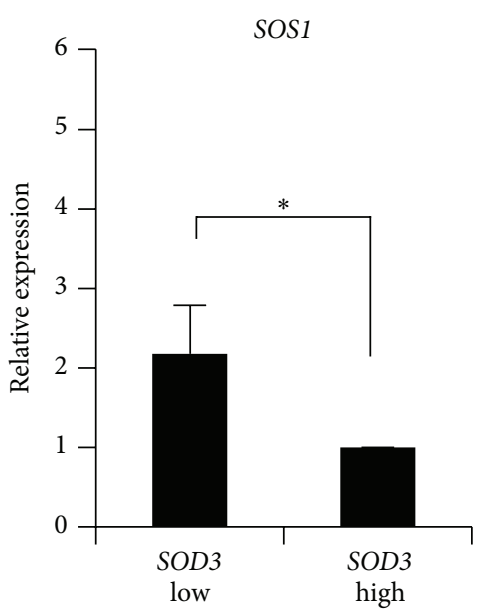

(g)

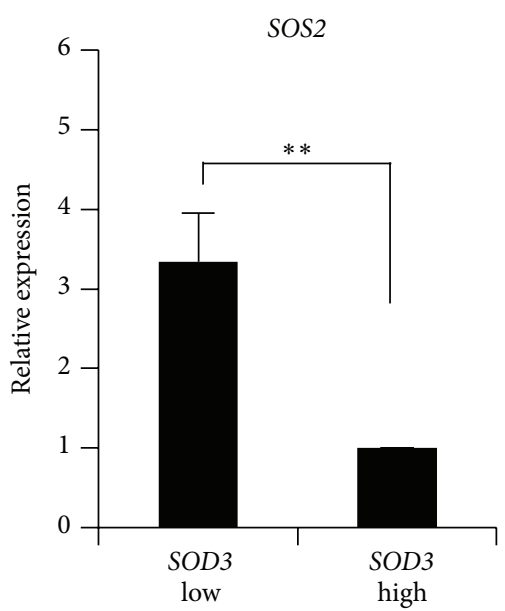

(h)

FIGURE 5: Self-regulation of SOD3 expression is mediated by GEF small GTPase regulatory proteins. (a-b) The analysis of the effects of low and high SOD3 transgene transfection on endogenous sod3 mRNA synthesis in rat PC E1A cells. Transfection of low amounts of human SOD3 into PC E1A cells significantly increased the endogenous rat sod3 expression, whereas high amounts of human SOD3 levels in PC E1A cells significantly reduced the endogenous rat sod 3 mRNA synthesis. (c-d) Western blot analysis of ERK1/2 phosphorylation in PC E1A cells suggested greater MAPK ERK1/2 activation at low SOD3 transgene expression levels compared to high transgene levels. (e) Comparison of rabbit transgene sod3 expression to human endogenous SOD3 mRNA synthesis in HEK 293T cells. The expression analysis performed on five consecutive days demonstrated a gradual decrease in the transgene expression that correlated with a gradual increase in the endogenous SOD3 mRNA synthesis. (f) The effect of the $\mathrm{H}_{2} \mathrm{O}_{2}$ concentration on SOD3 mRNA expression. HEK 293T cells were treated with different concentrations of $\mathrm{H}_{2} \mathrm{O}_{2}$. Low $\mathrm{H}_{2} \mathrm{O}_{2}$ concentrations caused increased SOD3 mRNA synthesis, and high $\mathrm{H}_{2} \mathrm{O}_{2}$ levels caused decreased SOD3 expression. (g) The effects of low and high SOD3 transgene expression on SOS1 and SOS2 GEF mRNA expression in 8505c cells. A low level of transgene expression caused an increase in SOS1 and SOS2 mRNA production, whereas high transgene SOD3 levels decreased the expression of both GEFs. The data are expressed as the mean \pm SD. The $p$ values are represented $\left({ }^{*} p<0.05,{ }^{* *} p<0.01\right.$, and $\left.{ }^{* * *} p<0.001\right)$.

causing this downregulation, we investigated the influence of the known regulatory factors in well-described thyroid cancer models systems in the current study.

Notably, the expression of SOD3 correlated with the activation level of RAS (Figure 1), suggesting that SOD3 is a ras oncogene-downregulated gene. Based on the data, the regulation of SOD3 mRNA expression in the thyroid cell models can be divided into immediate regulatory events, which are reversible and depend on the RAS activity, and late regulatory events, which cause long-term permanent silencing of the gene. The self-regulation mediated through RAS small GTPase regulatory genes may represent the fastest means of regulating SOD3 expression, which is required to maintain stable expression of the mRNA production and the redox balance in tissues. The guanine nucleotide exchange factors (GEF) small GTPase regulatory genes contribute to RAS activation by active removal of GDP that is then replaced by GTP with consequent immediate response in the downstream signal transduction. The current data suggest that even minor alterations in SOD3 expression significantly affect SOS1 and SOS2 GEF expression via a feedback loop, hence enabling response to sudden changes in signaling and fine adjustments of SOD3 production.

Recent papers have suggested that induction of mir21 transcription occurs through RAS-AP1 signaling [39] in a dose-dependent manner that correlates with RAS activity. While low RAS activity showed a minor impact on mir21 production, a striking increase in expression in cells with high
RAS activity [19] was observed; these results are in accord with the current data. Thus, the microRNA mir21 represents another immediate reversible regulatory step; however, this mechanism of regulation might require greater changes in RAS activation than GEF-mediated SOD3 regulation. The expression of mir21, which binds to the $3^{\prime} \mathrm{UTR}$ region of SOD3 mRNA [31], showed an inverse correlation with sod3 mRNA expression (Figures 1(c) and 1(d)), suggesting a sudden increase in mir 21 and decrease in sod3 expression at 10 -fold RAS activity. Therefore, the data suggest the importance of 10-fold RAS activity for cellular redox balance and mir21 target gene silencing. The microRNA mir21 is a well-characterized oncomir that is upregulated by RAS in the early stages of tumorigenesis. A recent paper has suggested that knockdown of mir21 in cells transplanted into mice significantly reduces tumorigenesis [40], underlining the importance of this microRNA in cancer development.

The third reversible RAS-dependent regulation step occurs through p38 MAPK activation. The ability of p38 MAPK to regulate SOD3 mRNA expression is noteworthy because the mitogen signaling cascade BRAF, MEK1/2, and ERK1/2 are primarily responsible for the stimulation of SOD3 synthesis. Although MAPK kinases follow specific signal transduction pathways to phosphorylate their cognate MAPKs (e.g., MEK1/2 activates ERK1/2 but not JNK), p38 MAPK displays selectivity between cognate and noncognate docking sites that might explain the interference between two signal transduction pathways [41]. However, we cannot 
exclude the possibility that the p38 MAPK inhibitor SB202190 is not specific for p38 or that negative feedback could activate alternative signal transduction pathways [42].

DNA methylation and histone acetylation represent more permanent DNA regulatory mechanisms compared to regulation controlled by GEFs, mir21, and p38 MAPK activation. DNA methylation, a stable modification that is often provoked by RAS, controls the expression of a number of genes through epigenetic mechanisms that recruit different transcriptional repressors in an orderly fashion. A recent publication has described step-by-step methylation silencing of the fas gene, suggesting coordinated action of 28 RAS-related epigenetic silencing effectors [17] that employ a well-organized signal transduction pathway. The silencing of RAS downstream genes is initiated by recruitment of PDK1, MAPK1, and $\mathrm{S} 100 \mathrm{Z}$ as the first step, followed by 14 other steps that eventually culminate in DNMT1 activation and consequent DNA methylation [43]. Although methylation changes are observed even in precancerous stages with chronic inflammation, the current data suggest the most prominent role for methylation-mediated SOD3 silencing in the presence of high RAS activity in advanced well-differentiated and poorly differentiated aggressive cancers. The first, the second, and the third exon of human SOD3 locate inside or at close proximity of $\mathrm{CpG}$ islands and repetitive elements, such as Alu and LINE 2B retrotransposons [33]. Although SOD3 promoter region is incompletely analyzed, it has been demonstrated that $\mathrm{CpG}$ methylation downregulates Sp1/Sp3 transcription factor binding to putative promoter region inhibiting SOD3 promoter activity and mRNA synthesis in vitro in human A549 adenocarcinoma lung alveolar basal epithelial cells [37] thus being in line with the current data.

The transcriptional silencing of genes caused by DNA methylation is further reinforced by histone deacetylase (HDAC) activity, which inhibits histone acetylation and causes the formation of closed chromatin structure and reduced DNA transcriptional activity. CpG dimer methylation-associated proteins, such as the transcriptional repressor $\mathrm{MeCP} 2$, attract multiprotein complexes that contain corepressor histone deacetylases [44], which then inhibit the expression of genes controlling the cell cycle, such as $p 21$, and promote uncontrolled growth and carcinogenesis [45]. The inhibition of HDAC function by TSA treatment had only a minor effect on sod3 expression in cancer cells or FRLT5 cells harboring high RAS activity (Figure 4). Instead, HDAC inhibition significantly decreased sod 3 mRNA production in cells that modeled normal rat thyroid. In normal thyroid, thyroid stimulating hormone (TSH) production is linked to histone acetylation; TSA treatment inhibits TSH promoter activity and therefore TSH production [46]. We have previously demonstrated that hormonal starvation reduces sod3 expression in thyroid cells, while TSH treatment stimulates sod3 production that is mediated by the cAMP-PKA and PLC-Ca ${ }^{2+}$ signal transduction pathways and affects normal thyroid cell proliferation [30]. The TSA-mediated reduction in SOD3 expression in human Nthy cells, which grow without hormone supplementation, suggests other TSH-independent mechanisms for gene regulation. However, the differences between human and rat cells could be caused by speciesspecific signal transduction [47], although indirect gene regulatory systems might also be involved.

In conclusion, the regulation of SOD3 expression in carcinogenesis involves ras oncogene-driven sequential events consisting of both reversible mechanisms that correlate with the RAS activation levels and more stable epigenetic events. Importantly, the use of multiple cell lines harboring different oncogenes and representing varying degrees of transformation in different species suggests that the regulation of SOD3 gene expression is not cell line-specific. Our current results thus suggest that SOD3 is a ras oncogene-downregulated gene.

\section{Conflict of Interests}

The authors have no conflict of interests.

\section{References}

[1] P.-O. Sjoquist and S. L. Marklund, "Endothelium bound extracellular superoxide dismutase type $\mathrm{C}$ reduces damage in reperfused ischaemic rat hearts," Cardiovascular Research, vol. 26, no. 4, pp. 347-350, 1992.

[2] M. O. Laukkanen, P. Leppanen, P. Turunen, T. Tuomisto, J. Naarala, and S. Yla-Herttuala, "EC-SOD gene therapy reduces paracetamol-induced liver damage in mice," Journal of Gene Medicine, vol. 3, no. 4, pp. 321-325, 2001.

[3] M. O. Laukkanen, A. Kivelä, T. Rissanen et al., "Adenovirusmediated extracellular superoxide dismutase gene therapy reduces neointima formation in balloon-denuded rabbit aorta," Circulation, vol. 106, no. 15, pp. 1999-2003, 2002.

[4] K. Ozumi, H. Tasaki, H. Takatsu et al., "Extracellular superoxide dismutase overexpression reduces cuff-induced arterial neointimal formation," Atherosclerosis, vol. 181, no. 1, pp. 55-62, 2005.

[5] E. D. van Deel, Z. Lu, X. Xu et al., "Extracellular superoxide dismutase protects the heart against oxidative stress and hypertrophy after myocardial infarction," Free Radical Biology and Medicine, vol. 44, no. 7, pp. 1305-1313, 2008.

[6] J. P. Laurila, L. E. Laatikainen, M. D. Castellone, and M. O. Laukkanen, "SOD3 reduces inflammatory cell migration by regulating adhesion molecule and cytokine expression," PLoS ONE, vol. 4, no. 6, Article ID e5786, 2009.

[7] M. D. Castellone, A. Langella, S. Cantara et al., "Extracellular superoxide dismutase induces mouse embryonic fibroblast proliferative burst, growth arrest, immortalization, and consequent in vivo tumorigenesis," Antioxidants and Redox Signaling, vol. 21, no. 10, pp. 1460-1474, 2014.

[8] M. O. Laukkanen, F. Cammarota, T. Esposito, M. Salvatore, and M. D. Castellone, "Extracellular superoxide dismutase regulates the expression of small gtpase regulatory proteins GEFs, GAPs, and GDI," PLoS ONE, vol. 10, no. 3, Article ID e0121441, 2015.

[9] J. P. Laurila, M. D. Castellone, A. Curcio et al., "Extracellular superoxide dismutase is a growth regulatory mediator of tissue injury recovery," Molecular Therapy, vol. 17, no. 3, pp. 448-454, 2009.

[10] H. L. Maecker, Z. Yun, H. T. Maecker, and A. J. Giaccia, "Epigenetic changes in tumor Fas levels determine immune escape and response to therapy," Cancer Cell, vol. 2, no. 2, pp. 139-148, 2002. 
[11] J. Sung, J. Turner, S. McCarthy et al., "Oncogene regulation of tumor suppressor genes in tumorigenesis," Carcinogenesis, vol. 26, no. 2, pp. 487-494, 2005.

[12] S. Cairns-Smith and P. Karran, "Epigenetic silencing of the DNA repair enzyme O6-methylguanine-DNA methyltransferase in Mex- human cells," Cancer Research, vol. 52, no. 19, pp. 52575263, 1992.

[13] H. Takada, I. Imoto, H. Tsuda et al., "ADAM23, a possible tumor suppressor gene, is frequently silenced in gastric cancers by homozygous deletion or aberrant promoter hypermethylation," Oncogene, vol. 24, no. 54, pp. 8051-8060, 2005.

[14] X. Qian, G. Li, H. K. Asmussen et al., "Oncogenic inhibition by a deleted in liver cancer gene requires cooperation between tensin binding and Rho-specific GTPase-activating protein activities," Proceedings of the National Academy of Sciences of the United States of America, vol. 104, no. 21, pp. 9012-9017, 2007.

[15] R. Holliday, "A new theory of carcinogenesis," British Journal of Cancer, vol. 40, no. 4, pp. 513-522, 1979.

[16] J. Covault, M. Perry, and R. Chalkley, "Effects of histone hyperacetylation and hypoacetylation on RNA synthesis in HTC cells," The Journal of Biological Chemistry, vol. 257, no. 22, pp. 13433-13440, 1982.

[17] C. Gazin, N. Wajapeyee, S. Gobeil, C.-M. Virbasius, and M. R. Green, "An elaborate pathway required for Ras-mediated epigenetic silencing," Nature, vol. 449, no. 7165, pp. 1073-1077, 2007.

[18] O. A. Kent and J. T. Mendell, "A small piece in the cancer puzzle: microRNAs as tumor suppressors and oncogenes," Oncogene, vol. 25, no. 46, pp. 6188-6196, 2006.

[19] G. De Vita, L. Bauer, V. M. Correa Da Costa et al., "Dosedependent inhibition of thyroid differentiation by RAS oncogenes," Molecular Endocrinology, vol. 19, no. 1, pp. 76-89, 2005.

[20] M. O. Laukkanen, P. Lehtolainen, P. Turunen et al., "Rabbit extracellular superoxide dismutase: expression and effect on LDL oxidation," Gene, vol. 254, no. 1-2, pp. 173-179, 2000.

[21] F. S. Ambesi-Impiombato, L. A. M. Parks, and H. G. Coon, "Culture of hormone-dependent functional epithelial cells from rat thyroids," Proceedings of the National Academy of Sciences of the United States of America, vol. 77, no. 6 I, pp. 3455-3459, 1980.

[22] A. Fusco, M. T. Berlingieri, P. P. Di Fiore, G. Portella, M. Grieco, and G. Vecchio, "One- and two-step transformations of rat thyroid epithelial cells by retroviral oncogenes," Molecular and Cellular Biology, vol. 7, no. 9, pp. 3365-3370, 1987.

[23] M. Grieco, M. Santoro, M. T. Berlingieri et al., "Molecular cloning of PTC, a new oncogene found activated in human thyroid papillary carcinomas and their lymph node metastases," Annals of the New York Academy of Sciences, vol. 551, pp. 380$381,1988$.

[24] M. Grieco, M. Santoro, M. T. Berlingieri et al., "PTC is a novel rearranged form of the ret proto-oncogene and is frequently detected in vivo in human thyroid papillary carcinomas," Cell, vol. 60, no. 4, pp. 557-563, 1990.

[25] R. Ralston and J. M. Bishop, "The protein products of the myc and $m y b$ oncogenes and adenovirus Ela are structurally related," Nature, vol. 306, no. 5945, pp. 803-806, 1983.

[26] M. Tiainen, D. Spitkovsky, P. Jansen-Dürr, A. Sacchi, and M. Crescenzi, "Expression of E1A in terminally differentiated muscle cells reactivates the cell cycle and suppresses tissuespecific genes by separable mechanisms," Molecular and Cellular Biology, vol. 16, no. 10, pp. 5302-5312, 1996.
[27] N. R. Lemoine, E. S. Mayall, T. Jones et al., "Characterisation of human thyroid epithelial cells immortalised in vitro by simian virus 40 DNA transfection," British Journal of Cancer, vol. 60, no. 6, pp. 897-903, 1989.

[28] T. Ito, T. Seyama, T. Mizuno et al., "Unique association of p53 mutations with undifferentiated but not with differentiated carcinomas of the thyroid gland," Cancer Research, vol. 52, no. 5, pp. 1369-1371, 1992.

[29] M. Xing, "BRAF mutation in thyroid cancer," Endocrine-Related Cancer, vol. 12, no. 2, pp. 245-262, 2005.

[30] L. E. Laatikainen, M. D. Castellone, A. Hebrant et al., "Extracellular superoxide dismutase is a thyroid differentiation marker down-regulated in cancer," Endocrine-Related Cancer, vol. 17, no. 3, pp. 785-796, 2010.

[31] X. Zhang, W.-L. Ng, P. Wang et al., "MicroRNA-21 modulates the levels of reactive oxygen species by targeting SOD3 and TNF $\alpha$, Cancer Research, vol. 72, no. 18, pp. 4707-4713, 2012.

[32] T. Kamiya, H. Hara, H. Yamada, H. Imai, N. Inagaki, and T. Adachi, "Cobalt chloride decreases EC-SOD expression through intracellular ROS generation and p38-MAPK pathways in COS7 cells," Free Radical Research, vol. 42, no. 11-12, pp. 949956, 2008.

[33] M. O. Laukkanen, S. Mannermaa, M. O. Hiltunen et al., "Local hypomethylation in atherosclerosis found in rabbit ec-sod gene," Arteriosclerosis, Thrombosis, and Vascular Biology, vol. 19, no. 9, pp. 2171-2178, 1999.

[34] L. E. Laatikainen, M. Incoronato, M. D. Castellone, J. P. Laurila, M. Santoro, and M. O. Laukkanen, "SOD3 decreases ischemic injury derived apoptosis through phosphorylation of Erk1/2, Akt, and Foxo3a," PLoS ONE, vol. 6, no. 8, Article ID e24456, 2011.

[35] P. Strålin and S. L. Marklund, "Multiple cytokines regulate the expression of extracellular superoxide dismutase in human vascular smooth muscle cells," Atherosclerosis, vol. 151, no. 2, pp. 433-441, 2000.

[36] T. Kamiya, H. Hara, N. Inagaki, and T. Adachi, "The effect of hypoxia mimetic cobalt chloride on the expression of EC-SOD in 3T3-L1 adipocytes," Redox Report, vol. 15, no. 3, pp. 131-137, 2010.

[37] I. N. Zelko, M. R. Mueller, and R. J. Folz, "CpG methylation attenuates Sp1 and Sp3 binding to the human extracellular superoxide dismutase promoter and regulates its cell-specific expression," Free Radical Biology and Medicine, vol. 48, no. 7, pp. 895-904, 2010.

[38] I. N. Zelko, M. W. Stepp, A. L. Vorst, and R. J. Folz, "Histone acetylation regulates the cell-specific and interferon-gammainducible expression of extracellular superoxide dismutase in human pulmonary arteries," American Journal of Respiratory Cell and Molecular Biology, vol. 45, no. 5, pp. 953-961, 2011.

[39] F. Talotta, A. Cimmino, M. R. Matarazzo et al., "An autoregulatory loop mediated by miR-21 and PDCD4 controls the AP-1 activity in RAS transformation," Oncogene, vol. 28, no. 1, pp. 7384, 2009.

[40] D. Frezzetti, M. De Menna, P. Zoppoli et al., "Upregulation of miR-21 by Ras in vivo and its role in tumor growth," Oncogene, vol. 30, no. 3, pp. 275-286, 2011.

[41] A. J. Bardwell, E. Frankson, and L. Bardwell, "Selectivity of docking sites in MAPK kinases," The Journal of Biological Chemistry, vol. 284, no. 19, pp. 13165-13173, 2009.

[42] P. Salerno, V. De Falco, A. Tamburrino et al., "Cytostatic activity of adenosine triphosphate-competitive kinase inhibitors in 
BRAF mutant thyroid carcinoma cells," Journal of Clinical Endocrinology and Metabolism, vol. 95, no. 1, pp. 450-455, 2010.

[43] N. Wajapeyee, S. K. Malonia, R. K. Palakurthy, and M. R. Green, "Oncogenic RAS directs silencing of tumor suppressor genes through ordered recruitment of transcriptional repressors," Genes and Development, vol. 27, no. 20, pp. 2221-2226, 2013.

[44] P. L. Jones, G. J. C. Veenstra, P. A. Wade et al., "Methylated DNA and MeCP2 recruit histone deacetylase to repress transcription," Nature Genetics, vol. 19, no. 2, pp. 187-191, 1998.

[45] V. M. Richon, T. W. Sandhoff, R. A. Rifkind, and P. A. Marks, "Histone deacetylase inhibitor selectively induces p21WAF1 expressjon and gene-associated histone acetylation," Proceedings of the National Academy of Sciences of the United States of America, vol. 97, no. 18, pp. 10014-10019, 2000.

[46] D. Wang, X. Xia, Y. Liu et al., "Negative regulation of tsh $\alpha$ target gene by thyroid hormone involves histone acetylation and corepressor complex dissociation," Molecular Endocrinology, vol. 23, no. 5, pp. 600-609, 2009.

[47] Y. Song, C. Massart, V. Chico-Galdo et al., "Species specific thyroid signal transduction: conserved physiology, divergent mechanisms," Molecular and Cellular Endocrinology, vol. 319, no. 1-2, pp. 56-62, 2010. 


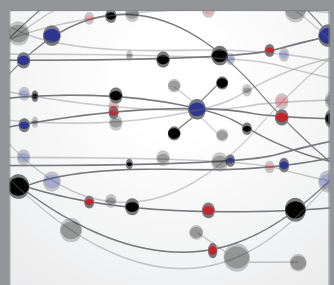

The Scientific World Journal
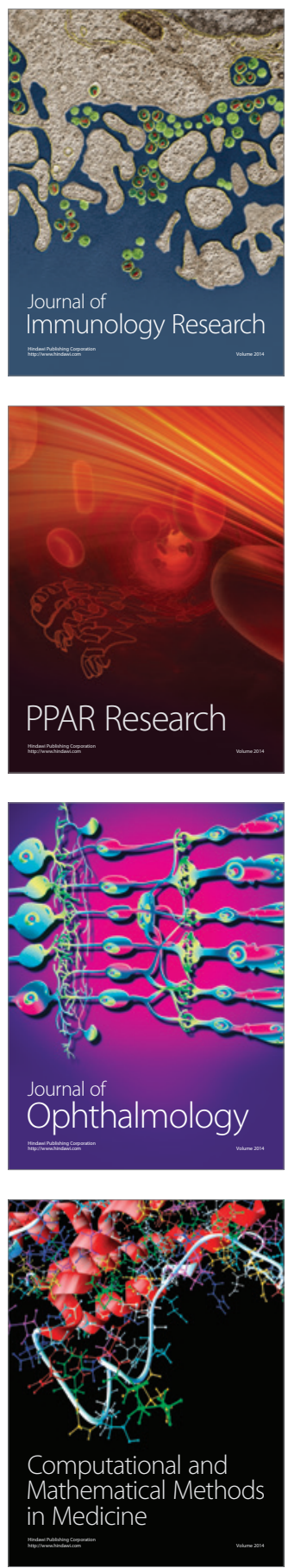

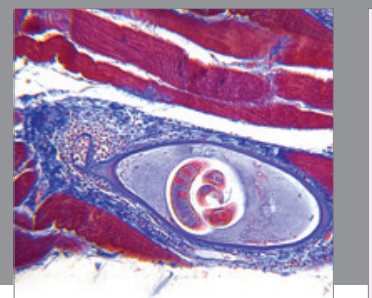

Gastroenterology

Research and Practice
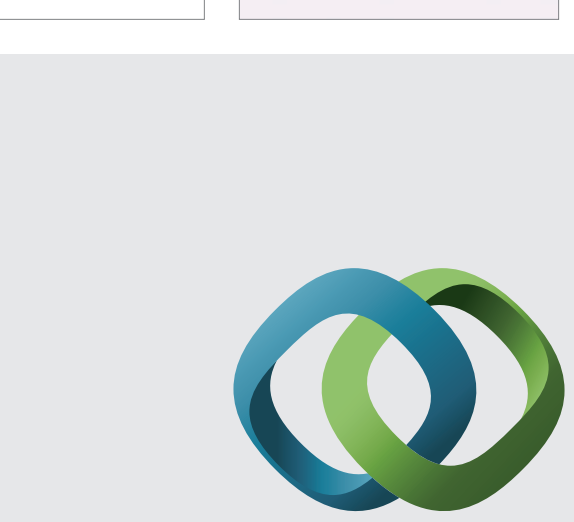

\section{Hindawi}

Submit your manuscripts at

http://www.hindawi.com
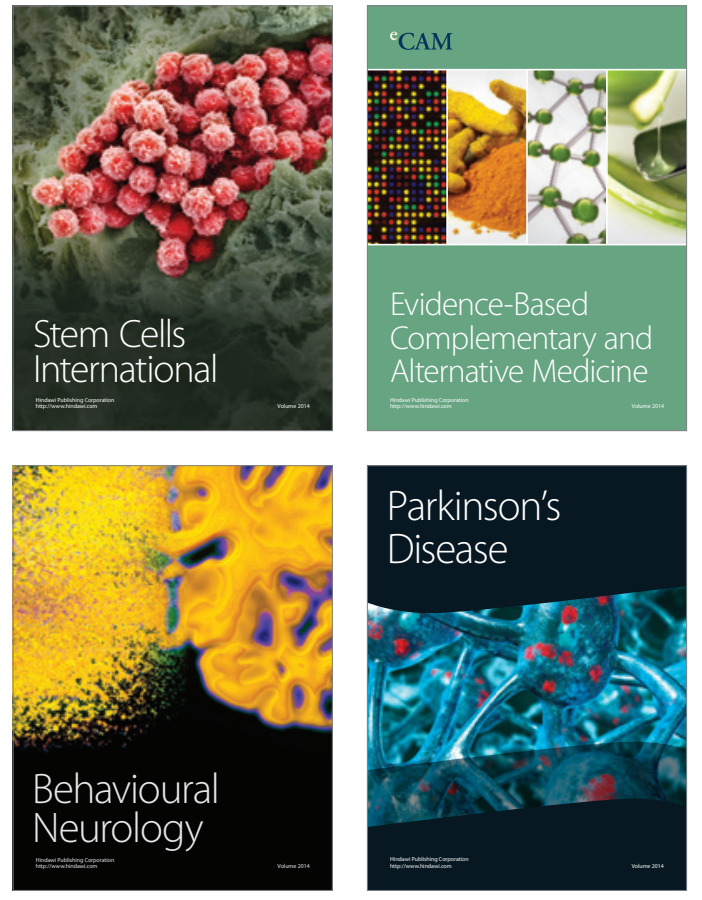
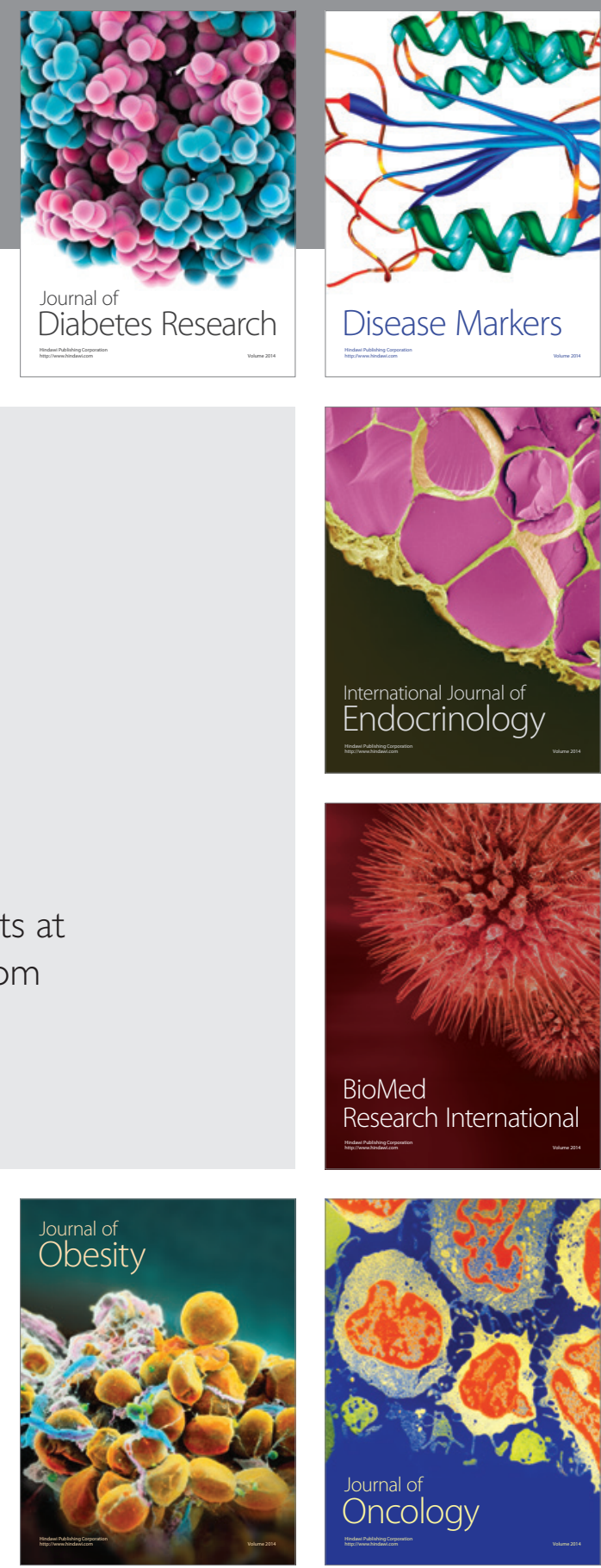

Disease Markers
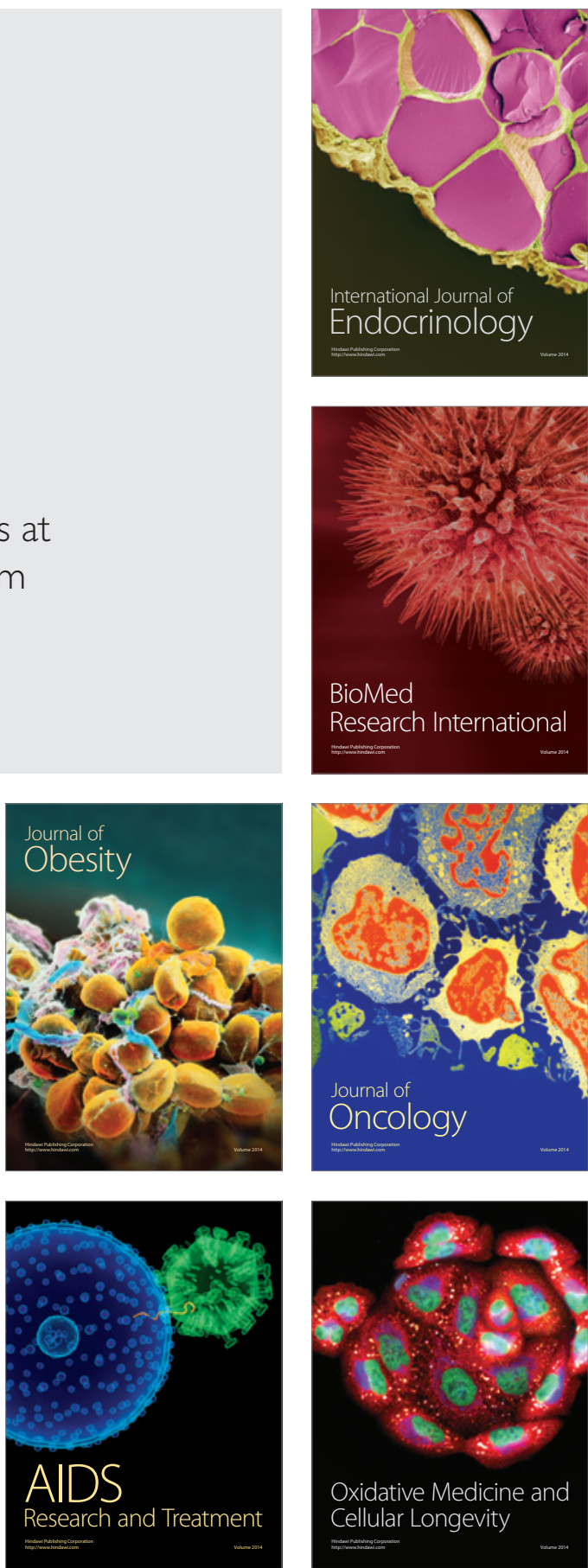